\begin{tabular}{|c|c|}
\hline Title & Synthesis, structure and photophysical properties of a flavin-based platinum(II) complex \\
\hline Author(s) & Kobay ashi, A tsushi; Ohbay ashi, Korin; A oki, Rie; Chang, Ho-Chol; Kato, Masako \\
\hline Citation & $\begin{array}{l}\text { Dalton Transactions, 40(14), 3484-3489 } \\
\text { https://doi.org/10.1039/c0dt01139h }\end{array}$ \\
\hline Issue Date & 2011-04-14 \\
\hline Doc URL & http:/hdl.handle.net/2115/48141 \\
\hline Rights & Dalton Trans., 2011, 40, 3484 3489- Reproduced by permission of The Royal Society of Chemistry (RSC) \\
\hline Type & article (author version) \\
\hline File Information & DT 40-14_3484-3489.pdf \\
\hline
\end{tabular}

Instructions for use 


\title{
Synthesis, Structure and Photophysical Properties of a Flavin-Based Platinum(II) Complex
}

\author{
Atsushi Kobayashi, $*^{a}$ Korin Ohbayashi, ${ }^{a}$ Rie Aoki, ${ }^{a}$ Ho-Chol Chang ${ }^{a}$ and Masako Kato* ${ }^{a}$ \\ Received (in $X X X, X X X) X$ th $X X X X X X X X X 200 X$, Accepted $X$ th $X X X X X X X X X 200 X$ \\ ${ }_{5}$ First published on the web Xth $X X X X X X X X X 200 X$ \\ DOI: $10.1039 / b 000000 x$
}

We synthesized a thiosemicarbazone-functionalized flavin (FI-(H)TSC: 2-[2-(3,4-dihydro-7,8dimethyl-2,4-dioxobenzo[g]pteridin-10(2H)-yl)ethylidene]-hydrazinecarbothioamide) and its $\mathrm{Pt}(\mathrm{II})$ complex [Pt(Fl-TSC) $)_{2}$ ], and characterized it using X-ray diffraction, UV-visible absorption and

10 luminescence spectroscopy. X-ray structural analysis for $\left[\mathbf{P t}(\mathbf{F l - T S C})_{2}\right.$ ] revealed that the structure of the isoalloxazine part was almost the same as that in lumiflavin (7,8,10-trimethylisoalloxazine), and the thiosemicarbazone moiety acted as a bidentate ligand to form a $\mathrm{PtS}_{2} \mathrm{~N}_{2}$ planar conformation. UV-visible absorption and luminescence spectra of these compounds were very similar to those of riboflavin, but the emission intensity and the lifetime decreased considerably. Theoretical

15 calculations suggested that the charge-separated state $\left(\mathrm{Fl}^{\bullet-}-\mathrm{TSC}^{\bullet+}\right)$ contributed to the faster quenching from the ${ }^{1} \pi-\pi^{*}$ emission state.

\section{Introduction}

Isoalloxazines (10-substituted-2,3,4,10-tetrahydro-benzo[g] pteridine-2,4-diones), especially flavins (7,8-dimethyl 20 substituted isoalloxazines), are interesting compounds because of their biological functions. ${ }^{1-2}$ For example, flavins play an important role in various redox transformations, including the oxidation of amines to imines, thiols to disulfides and the hydroxylation of aromatic species. ${ }^{3}$ One of the best known 25 members of this family is riboflavin (vitamin $\mathrm{B}_{2}, 10-(2,3,4,5-$ tetrahydroxypentyl)-7,8-dimethylbenzo[g]pteridine- $2,4(3 \mathrm{H}$, $10 \mathrm{H}$ )-dione)). Many researchers have studied the biological, chemical and photophysical properties of riboflavin and its derivatives. ${ }^{4-7}$ The redox activities of flavins drastically 30 change due to photoexcitation of the ground state. Therefore, flavoenzymes and flavin analogues possess rich photochemistry and photobiology. ${ }^{6-7}$ Their interesting properties are mainly due to the characteristic isoalloxazine ring system, which allows them to participate in many 35 catalytic reactions. ${ }^{8}$ Therefore, most studies have focused on changes of the flavin chromophore redox potentials caused by non-covalent interactions. In contrast, studies focussing on the modification of the ribitol side chain of riboflavin to form metal-complexes have been rare. ${ }^{9}$

40 In this work, our attention has been focused on the side chain modification of the flavin molecule to create a new functional molecule based on the photoactivity of flavin moiety. We chose a thiosemicarbazone group as the substituent group, because this can act as a bidentate coordination ligand to form

45 various metal complexes and some of them exhibit interesting cytotoxic activities. ${ }^{10-11}$ Combination of the flavin moiety and thiosemicarbazone-metal complex may enable us to achieve light-induced pharmacological activity. In this paper, as the first step, we report the syntheses, crystal structures and ${ }_{50}$ photophysical properties of two flavin derivatives, thiosemicarbazone-functionalized flavin (FI-(H)TSC) and its
Pt(II) complex [Pt(Fl-TSC) 2 ] (see Scheme 1) based on X-ray diffraction, UV-visible absorption and luminescence spectroscopy, luminescence lifetime, quantum yield 55 measurements and theoretical calculations.<smiles></smiles>

$\mathrm{FI}-(\mathrm{H}) \mathrm{TSC}$

Scheme 1. Structural representation of flavin derivatives discussed in this study.

\section{Results and Discussion}

${ }_{60}$ Crystal structure of Fl-(H)TSC ligand. Figure 1 shows the molecular structure of Fl-(H)TSC. Table 1 lists selected bond distances. The compound Fl-(H)TSC was crystallized in the triclinic $P-1$ space group. The results of single crystal X-ray structural analysis for Fl-(H)TSC clearly indicate that the ${ }_{65}$ thiosemicarbazide chain substitutes the ribitol side chain of riboflavin. In the isoalloxazine ring, it should be noted that the 
N1-C12 and N3-C3 bond distances are remarkably shorter than the other $\mathrm{N}-\mathrm{C}$ bond distances in the isoalloxazine ring. The flavin moiety can accept two protons at the N1 and N3 positions and can also accept two electrons. ${ }^{2}$ Judging from the 5 bond distances around the nitrogen atoms mentioned above, ${ }^{12}$ the isoalloxazine portion is in the neutral state and only has one proton at the $\mathrm{N} 2$ position. All atoms of the thiosemicarbazone portion $(=\mathrm{N} 5-\mathrm{N} 6-\mathrm{C} 15(=\mathrm{S} 1)-\mathrm{N} 7)$ are located at the same plane. The observed S1-C15 and N5-N6 10 bond distances were close to the typical values of
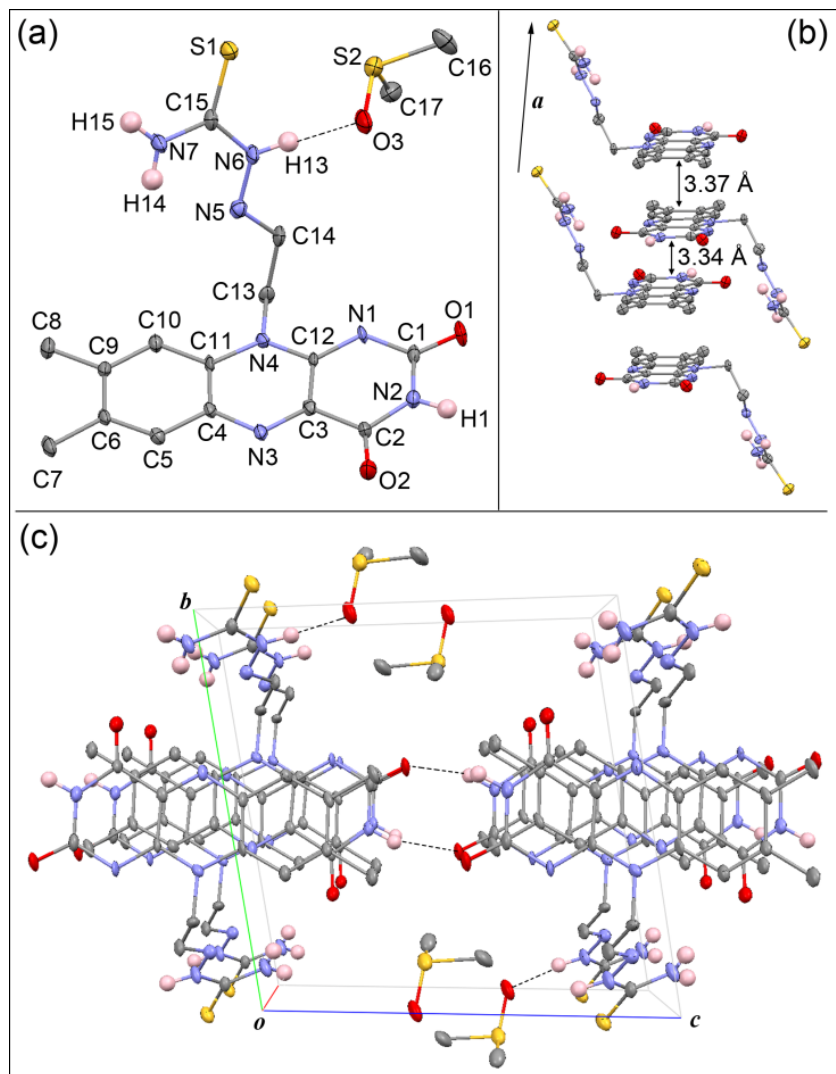

Fig. 1. (a) Molecular structure of Fl-(H)TSC, (b) 1-D stacking structure and (c) packing diagram viewed down along the $a$ axis with thermal vibrational ellipsoids at the $50 \%$ probability level. $\mathrm{H}$ atoms bound to $\mathrm{C}$ atoms are omitted for clarity. Dotted line shows hydrogen bonds.

Table 1. Selected bond lengths ( $\AA$ ) of Fl-(H)TSC and [Pt(Fl-TSC) $)_{2}$.

\begin{tabular}{ccc}
\hline & Fl-(H)TSC & $\left.[\text { Pt(Fl-TSC) }]_{2}\right]$ \\
\hline N1-C1 & $1.380(6)$ & $1.361(4)$ \\
N1-C12 & $1.331(5)$ & $1.325(4)$ \\
N2-C1 & $1.381(6)$ & $1.399(4)$ \\
N2-C2 & $1.391(5)$ & $1.374(4)$ \\
C1-O1 & $1.227(5)$ & $1.234(4)$ \\
C2-O2 & $1.202(6)$ & $1.211(4)$ \\
N3-C3 & $1.310(5)$ & $1.298(3)$ \\
N3-C4 & $1.374(6)$ & $1.359(3)$ \\
N4-C11 & $1.395(5)$ & $1.393(4)$ \\
N4-C12 & $1.359(6)$ & $1.357(3)$ \\
C3-C12 & $1.443(6)$ & $1.454(4)$ \\
N5-N6 & $1.370(6)$ & $1.394(5)$ \\
N6-C15 & $1.359(6)$ & $1.311(4)$ \\
N7-C15 & $1.328(6)$ & $1.356(6)$ \\
S1-C15 & $1.695(5)$ & $1.741(4)$ \\
Pt1-S1 & - & $2.289(1)$ \\
Pt1-N5 & - & $2.025(3)$ \\
\end{tabular}

thiosemicarbazone derivatives. ${ }^{13}$ As shown in Figure 1(b), isoalloxazine rings were stacked along the $a$ axis with 20 moderate $\pi-\pi$ interaction $(3.340-3.370 \AA)$. One Fl-(H)TSC molecule formed three hydrogen bonds. One was a hydrogen bond with solvated DMSO molecules through N6 with an N6 $\cdots \mathrm{O} 3$ distance of about $2.785 \AA$. The others were NH-Otype double hydrogen bonds with the $\mathrm{O} 1$ and N2 atoms $(2.863$ ${ }_{25} \AA$ ) of another Fl-(H)TSC molecule in the unit cell.

Crystal structure of the $\left[\mathrm{Pt}(\mathrm{Fl}-\mathrm{TSC})_{2}\right]$ complex. Figure 2(a) shows the molecular structure of [Pt(Fl-TSC) $)_{2}$ ]. Table 1 shows selected bond distances. As shown in Figure 2(a), the $\mathrm{Pt}(\mathrm{II})$ ion was surrounded by two Fl-(H)TSC ligands to form 30 a neutral [Pt(Fl-TSC) $)_{2}$ ] molecule. Because the Pt(II) ion was located on the inversion center of the $P-1$ space group, the two Fl-(H)TSC ligands in this molecule were crystallographically equivalent. Compared to the Fl-(H)TSC ligand, the N5-N6, S1-C15 and N7-C15 bond distances 35 increased more in [Pt(Fl-TSC $)_{2}$ ] than those in the Fl-(H)TSC ligand. In contrast, the N6-C15 bond distance in

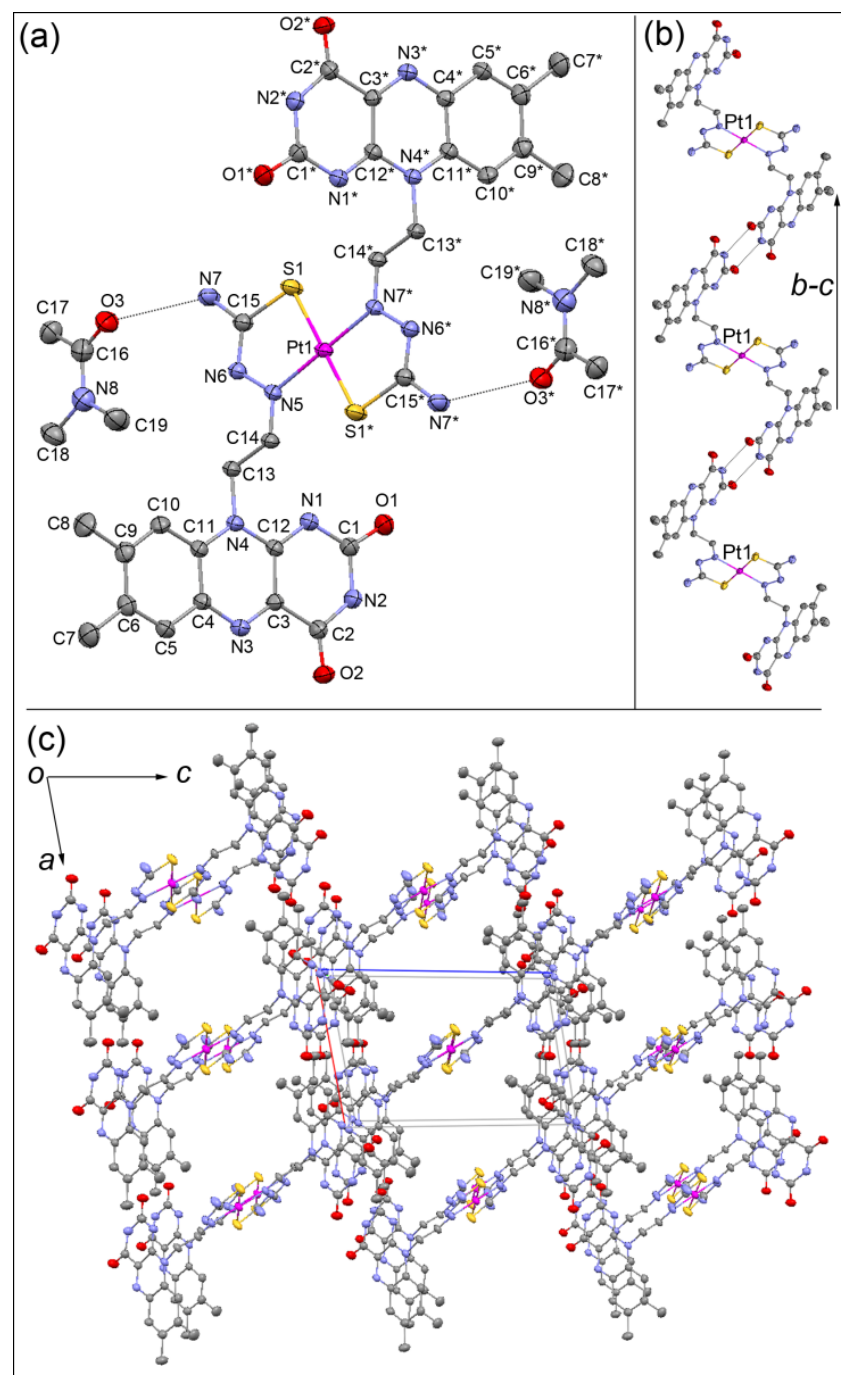

Fig. 2. (a) Molecular structure of [Pt(Fl-TSC) $)_{2}$ ], (b) 1-D hydrogen bonding chain along the $b-c$ axis and (c) Packing diagram viewed down 40 along the $b$ axis with thermal vibrational ellipsoids at the $50 \%$ probability level. $\mathrm{H}$ atoms are omitted for clarity. Solvated DMA molecules are omitted for clarity in Figs. 2(b) and (c). 
[Pt(Fl-TSC) $)_{2}$ ] was remarkably shorter (about $0.048 \AA$ ) than that in Fl-(H)TSC. These changes clearly indicate that the thiosemicarbazone portion was deprotonated and then bound to the Pt(II) ion. It is well known that the thiosemicarbazone 5 derivatives can bind to various metal ions accompanied by the deprotonation of the $=\mathrm{N}-\mathrm{NH}-$ portion. ${ }^{13}$ The $\mathrm{Pt}-\mathrm{S}$ bond distance was close to the typical value. The torsion angle between the $\mathrm{PtS}_{2} \mathrm{~N}_{2}$ coordination plane and the isoalloxazine ring was about $70^{\circ}$. Because the other bond distances of the 10 isoalloxazine portion were almost the same as those of the Fl(H)TSC ligand, the effect of Pt complex formation on the isoalloxazine ring was small. Figure 2(b) shows the 1-D hydrogen bond network of the $\left[\mathbf{P t}(\mathbf{F l}-\mathbf{T S C})_{2}\right]$. In addition to the Fl-(H)TSC ligand, the [Pt(Fl-TSC) $\left.)_{2}\right]$ molecule also 15 fomed a double NH-O-type hydrogen bond between two molecules. One of the three solvated dimethyl acetoamide (DMA) molecules was hydrogen bonded to the N7 atoms of the thiosemicarbazone side chain. Due to the Pt complex formation, the hydrogen bond network formed by the [Pt(Fl$\left.{ }_{20} \mathbf{T S C}\right)_{2}$ ] molecules was an infinite 1-D zigzag chain structure. Two isoalloxazine rings were dimerized via a moderate $\pi-\pi$ stacking interaction $(3.237 \AA)$, but this dimer was isolated and surrounded by solvated DMA molecules. It is interesting that there were six DMA molecules in one unit cell, suggesting 25 that the occupied volume of the DMA molecules in the unit cell was above half of the unit cell volume $\left(\sim 55.0 \%\right.$; $863.2 \AA^{3}$ calculated by platon squeeze program). ${ }^{14}$

Spectroscopic properties. In order to clarify the chemical modification effects of the ribitol side chain on the electronic 30 state of the isoalloxazine ring, we performed UV-visible

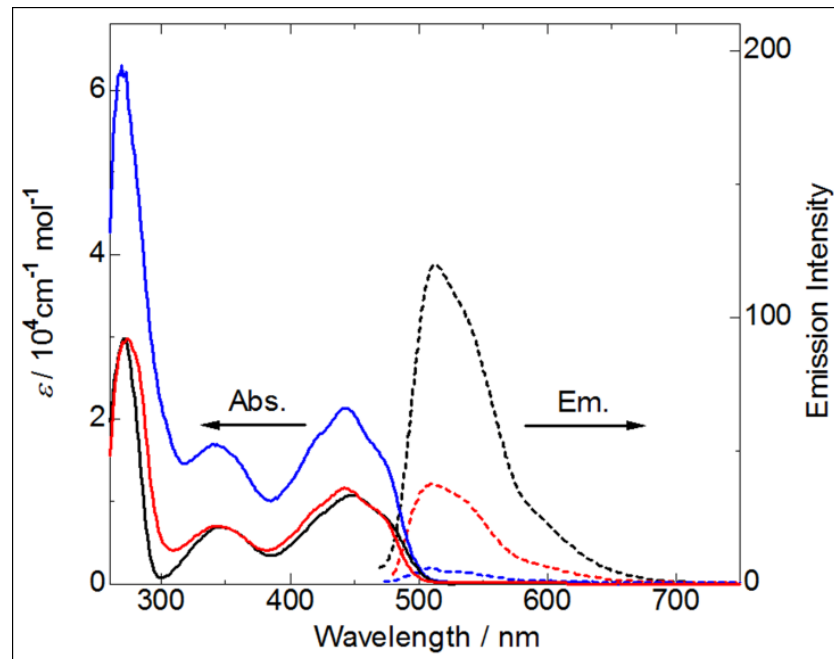

Fig. 3. UV-visible absorption (solid lines) and luminescence spectra (dotted lines, $\lambda_{\text {ex. }}=450 \mathrm{~nm}$ ) of riboflavin (black), Fl-(H)TSC (red) and [Pt(Fl-TSC) $)_{2}$ (blue) in DMSO solution.

35 Table 2. Spectroscopic properties of riboflavin, Fl-(H)TSC and [Pt(FlTSC) $)_{2}$ ] compounds.

\begin{tabular}{cccccc}
\hline Compound & $\begin{array}{c}\lambda_{\text {abs. }} \\
(\max ) / \mathrm{nm}\end{array}$ & $\varepsilon_{\text {max }} / \mathrm{M}^{-1} \mathrm{~cm}^{-1}$ & $\begin{array}{c}\lambda_{\mathrm{em} .} \\
(\max ) / \mathrm{nm}\end{array}$ & $\tau_{\mathrm{em}} / \mathrm{ns}$ & $\Phi_{\mathrm{em} .}$ \\
\hline Riboflavin & 448 & 10780 & 513 & 2.35 & 0.11 \\
Fl-(H)TSC & 443 & 11600 & 510 & 0.83 & 0.01 \\
{$[$ Pt(Fl-TSC) 2$]$} & 443 & 21300 & 510 & 0.83 & $0.002^{\mathrm{a}}$ \\
${ }^{a}$ Determined by comparison to the known quantum yield of riboflavin. \\
\hline
\end{tabular}

absorption and luminescence spectroscopies. Table 2 summarizes the spectroscopic parameters discussed in this 40 section. Figure 3 shows the absorption and luminescence spectra of riboflavin, the Fl-(H)TSC ligand and the [Pt(FITSC) $)_{2}$ ] complex. For riboflavin, according to the previous reports, ${ }^{6}$ three observed absorption bands centered at 278,348 and $455 \mathrm{~nm}$ were assigned to the $\pi-\pi^{*}$ transitions based on the 45 isoalloxazine rings, and the emission band centered at $513 \mathrm{~nm}$ to the fluorescence from the ${ }^{1} \pi-\pi^{*}$ transition state. In contrast to the absorption spectrum of riboflavin, Fl-(H)TSC and [Pt(Fl-TSC) $)_{2}$ ] exhibited very similar spectra. The $\varepsilon$ value of the [Pt(Fl-TSC $)_{2}$ ] was almost twice as large as those of the 50 other compounds, being consistent with the fact that the complex has two isoalloxazine portions in one molecule. Although the emission energies of Fl-(H)TSC and [Pt(FlTSC) $)_{2}$ ] were also similar (510 nm for both compounds) to that of riboflavin, the emission intensities of both compounds 55 significantly decreased as compared with that of riboflavin. Observed luminescence quantum yields of the Fl-(H)TSC ligand and the $\left[\mathbf{P t}(\mathbf{F l}-\mathbf{T S C})_{2}\right]$ complex were approximately one tenth and one fiftieth, respectively, that of riboflavin. The emission lifetime of [Pt(Fl-TSC) $)_{2}$ ] was almost the same as 60 that of Fl-(H)TSC in spite of the smaller quantum yield (see Figure S1). These results might be due to the faster electron transfer from the isoalloxazine ring to the $\operatorname{Pt}(\mathrm{TSC})_{2}$ moiety to form more stable charge-separated state than that in Fl(H)TSC ligand (see below). These results suggest that the 65 chemical modification of the side chain bound to the N4 position of the isoalloxazine ring did not affect the ground state, but remarkably affected the excited state. In fact, to estimate the redox potential of the ground state of each compound, we measured the cyclic voltammograms for 70 riboflavin, Fl-(H)TSC and [Pt(Fl-TSC) $)_{2}$ ] and the obtained voltamnmograms were almost the same (see Figure S2).

Molecular orbital calculations. As discussed above, the chemical modification of the ribitol chain of riboflavin remarkably affected the emission property derived from the $\pi$ $75 \pi^{*}$ excited state mainly delocalized on the isoalloxazine ring. In order to investigate in more detail, we performed molecular orbital calculations based on density functional theory. Figure 4 shows the highest occupied molecular orbital (HOMO) and lowest unoccupied molecular orbital (LUMO) of the three ${ }_{80}$ compounds riboflavin, Fl-(H)TSC ligand and [Pt(Fl-TSC) $)_{2}$ ] complex. Both the HOMO and LUMO of riboflavin are $\pi$ - and $\pi^{*}$-orbital localized on the isoalloxazine moiety. ${ }^{6}$ Our calculation results for riboflavin were consistent with previous reports. ${ }^{6}$ Although the LUMO of each compound was 85 localized on the isoalloxazine moiety, the HOMOs of Fl(H)TSC and [Pt(Fl-TSC) $)_{2}$ ] were completely different than that of riboflavin. The HOMOs were localized on the thiosemicarbazone and $\mathrm{Pt}(\mathrm{TSC})_{2}$ moieties, respectively, as shown in Figures 4(c) and 4(e). The $\pi$-orbital localized on the 90 isoalloxazine portion, similar to the HOMO of riboflavin, was HOMO-1, which locates lower by about 0.3 and $0.5 \mathrm{eV}$ than the HOMOs of Fl-(H)TSC and [Pt(Fl-TSC) $)_{2}$, respectively (see Figure S3). In this electronic state, the thiosemicarbazone moiety can function as an electron donor in the $\pi-\pi^{*}$ excited 95 state. In other words, an electron transfer process from the 
thiosemicarbazone side chain to the isoalloxazine moiety to
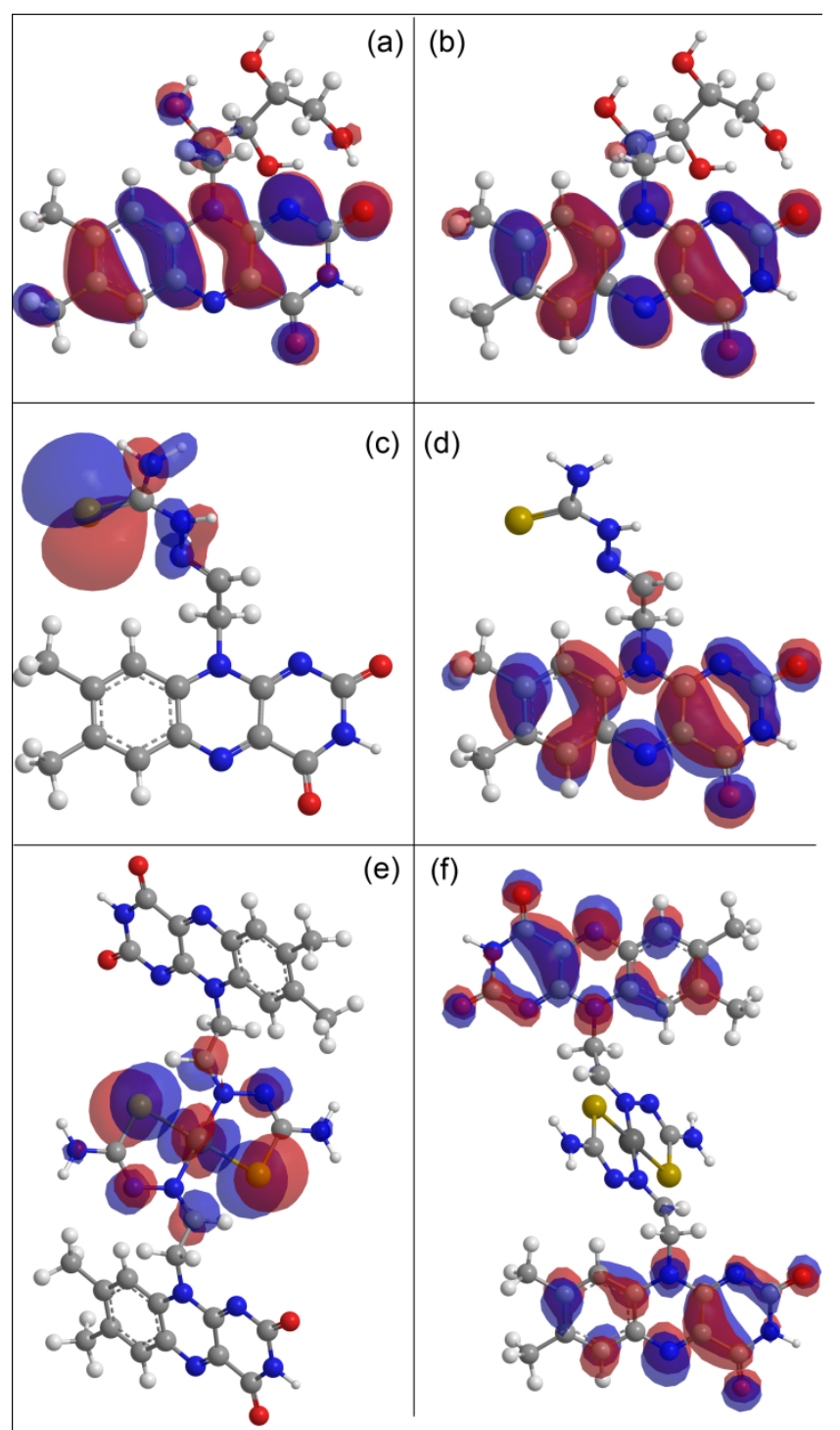

(e) (f)

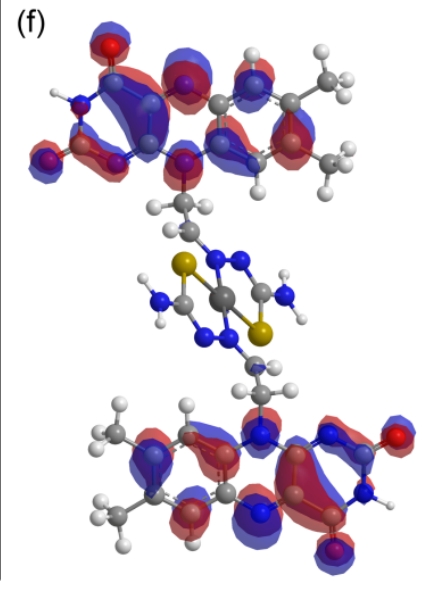

Fig. 4. The shape of the highest occupied molecular orbital (HOMO) and the lowest unoccupied molecular orbital (LUMO) of riboflavin (a, b), Fl5 (H)TSC (c, d) and [Pt(Fl-TSC) $)_{2}$ (e, f). The isosurfaces correspond to the value of \pm 0.02 .

form a charge-separated state $\left(\mathrm{Fl}^{0^{--}}-\mathrm{TSC}^{\bullet+}\right)$ would be induced after the photoexcitation of the $\pi-\pi^{*}$ transition, resulting in non-radiation charge-recombination quenching from the 10 charge-separated state. In addition, for the [Pt(FI-TSC) $)_{2}$ ] complex, the energy transfer between the two isoalloxazine moieties might also be one of the origins of the lower emission quantum yield.

\section{Conclusions}

15 We have successfully synthesized a thiosemicarbazone-Pt(II) complex ([Pt(Fl-TSC) $\left.\left.)_{2}\right]\right)$ that possesses a flavin moiety. X-ray structural analyses of the modified flavin ligand, Fl-(H)TSC and [Pt(Fl-TSC $)_{2}$ ] revealed that the bond lengths and angles of the isoalloxazine moiety were almost the same as those of lumiflavin. 20 Thiosemicarbazone moiety acted as a bidentate ligand to form the
Pt complex [Pt(Fl-TSC) $)_{2}$. UV-visible absorption and luminescence spectra of these compounds possessed shapes very similar to each other, but the emission quantum yields and lifetimes of Fl-(H)TSC and [Pt(Fl-TSC $)_{2}$ ] were both lesser and ${ }_{25}$ shorter than those of riboflavin. Theoretical calculations based on density functional theory suggested that the electron transfer process from the thiosemicarbazone moiety to the isoalloxazine portion contributed to faster quenching from the $\pi-\pi^{*}$ emission state via the charge-separated state $\left(\mathrm{Fl}^{\bullet-}-\mathrm{TSC}^{\bullet+}\right)$. Further 30 investigation of the photoreactivities of these compounds is currently in progress.

\section{Experimental}

Syntheses. All starting materials, riboflavin, thiosemicarbazide and $\mathrm{K}_{2} \mathrm{PtCl}_{4}$ were used as purchased from 35 Tokyo Chemical Industries, Co., Ltd. Japan and the solvents were used without any purification. We prepared $\left[\mathrm{PtCl}_{2}(\mathrm{PhCN})_{2}\right]$ according to published methods. ${ }^{15}$ Elemental analysis was performed at the analysis centre at Hokkaido University. ${ }^{1} \mathrm{H}$ NMR were recorded on a JEOL JNM-EX270

${ }_{40}$ FT NMR SYSTEM with chemical shifts (in ppm) relative to tetramethylsilane.

Fl-(H)TSC. We prepared 2-(2-(7,8-dimethyl-2,4-dioxo-3,4dihydrobenzo[g]pteridin-10(2H)-yl)ethylidene)hydrazine-

carbothioamide by a procedure similar to a literature 45 method. ${ }^{16}$ Riboflavin $(500 \mathrm{mg}, 1.33 \mathrm{mmol})$ was dissolved in $0.1 \mathrm{M} \mathrm{NaOH}$ aqueous solution $(20 \mathrm{~mL})$ in a light-resistant flask. We cooled the solution at $273 \mathrm{~K}$ in an ice bath and then added a warmed lead(IV) acetate $(2.0 \mathrm{~g}, 4.51 \mathrm{mmol})$ solution in acetic acid $(20 \mathrm{~mL})$ slowly. After subsequent stirring for 10 $50 \mathrm{~min}$ at $273 \mathrm{~K}$, a hot, aqueous solution of thiosemicarbazide (500 mg, $5.49 \mathrm{mmol}$ ) was added. We slowly heated the mixed solution to $318 \mathrm{~K}$ at which point a reddish orange precipitate emerged. This precipitate was isolated by filtration, washed with $95 \%$ acetic acid, water, methanol and diethylether, and ${ }_{55}$ dried in vacuo to yield a reddish orange powder of Fl-(H)TSC in a $91.7 \%$ yield. We obtained a single crystal of Fl-(H)TSC suitable for X-ray structural determination via the diffusion method of $\mathrm{DMSO} / \mathrm{MeOH}$ at room temperature. Elemental analysis calcd. for $\mathrm{C}_{15} \mathrm{H}_{15} \mathrm{~N}_{7} \mathrm{O}_{2} \mathrm{~S}_{1}$. DMSO: $\mathrm{C} 46.88 ; \mathrm{H} \mathrm{4.86;} \mathrm{N}$ 60 22.51. Found: C 46.14; H 4.80; N 22.91. ${ }^{1} \mathrm{H}$ NMR (DMSO-d 6 ,

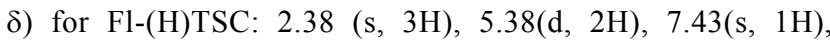
7.53(t, 1H), 7.71(s, 1H), 7.89(s, 1H), 7.97(s, 1H), 11.32(s, 1H), $11.36(\mathrm{~s}, 1 \mathrm{H})$.

[Pt(Fl-TSC) $)_{2}$. A mixture of $\left[\mathrm{PtCl}_{2}(\mathrm{PhCN})_{2}\right]$ (46 mg, 0.097 $\left.{ }_{65} \mathrm{mmol}\right)$ and Fl-(H)TSC $(70 \mathrm{mg}, 0.097 \mathrm{mmol})$ in methanol (6 $\mathrm{mL}$ ) was refluxed for $3 \mathrm{~h}$. The resulting brown precipitate was collected by filtration, washed with a small amount of methanol (less than $0.5 \mathrm{~mL}$ ) and dried in vacuo to afford a brown powder [Pt(Fl-TSC) $)_{2}$ ] in a $49.7 \%$ yield. Elemental 70 analysis calcd. for $\mathrm{C}_{30} \mathrm{H}_{28} \mathrm{~N}_{14} \mathrm{O}_{4} \mathrm{~S}_{2} \mathrm{Pt} \cdot 6 \mathrm{H}_{2} \mathrm{O}$ : C 35.47; $\mathrm{H} 3.97$; N 19.30; found: C 35.61, H 3.75, N 18.75. ${ }^{1} \mathrm{H}$ NMR (DMSO- $d_{6}$, ס) for $\left[\mathrm{Pt}(\mathrm{Fl}-\mathrm{TSC})_{2}\right]: 2.41(\mathrm{~s}, 3 \mathrm{H}), 5.59(\mathrm{~d}, 2 \mathrm{H}), 7.10(\mathrm{t}, 1 \mathrm{H})$, 7.43(d, 2H), 7.63(s, 1H), 7.93(s, 1H), 11.37(s, 1H). A single crystal of the [Pt(Fl-TSC) $)_{2}$ ] complex suitable for X-ray 75 structural determination was obtained via natural evaporation of a DMA solution at room temperature for several weeks. 
Single-crystal X-ray diffraction measurements. We mounted a single crystal on a MicroMount with paraffin oil. Because the single crystal of Fl-(H)TSC was very small, Xray structural analysis for Fl-(H)TSC was performed using a ${ }_{5}$ Rigaku MERCURY CCD diffractometer with a NW2A beamline of the Advanced Ring (Photon Factory of KEK; Japan). The wavelength of the synchrotron X-ray was 0.6890(1) A. All measurements of [Pt(Fl-TSC) $)_{2}$ ] were performed using a Rigaku AFC-7R diffractometer with a 10 mercury CCD area detector, graphite monochromated Mo-K $\alpha$ radiation $(\lambda=0.71069 \AA)$ and a rotating anode generator. We used a nitrogen gas flow temperature controller to cool the sample. Diffraction data were collected and processed with CrystalClear. ${ }^{17}$ The structure was solved by a direct method 15 using SIR2004 ${ }^{18}$ and refined by the full-matrix least-squares method using SHELXL-97. ${ }^{19}$ The non-hydrogen atoms were refined anisotropically. $\mathrm{H}$ atoms were refined using the riding model. We performed all calculations using the CrystalStructure crystallographic software package ${ }^{20}$ except 20 for the refinement calculations, which we performed using SHELXL-97. Table 3 summarizes the crystallographic data for Fl-(H)TSC and [Pt(Fl-TSC) $)_{2}$. Full crystallographic details have been deposited with the Cambridge Crystallographic Data Centre under the supplementary ${ }_{25}$ publication No. CCDC-790484-790485.

Table 3. Crystallographic data for Fl-(H)TSC and [Pt(Fl-TSC) $)_{2}$.

\begin{tabular}{|c|c|c|}
\hline Complex & Fl-(H)TSC & {$\left[\mathrm{Pt}(\mathrm{Fl}-\mathrm{TSC})_{2}\right]$} \\
\hline Chemical formula & $\mathrm{C}_{15} \mathrm{H}_{15} \mathrm{~N}_{7} \mathrm{O}_{2} \mathrm{~S}_{1} \cdot \mathrm{DMSO}$ & $\begin{array}{c}\mathrm{C}_{30} \mathrm{H}_{28} \mathrm{~N}_{14} \mathrm{O}_{4} \mathrm{Pt} \mathrm{S}_{2} \\
\text { 6DMA }\end{array}$ \\
\hline Temperature / K & 120 & 150 \\
\hline Crystal system & Triclinic & Triclinic \\
\hline Space group & $P-1$ & $P-1$ \\
\hline$a[\AA]$ & $6.809(5)$ & $10.022(3)$ \\
\hline$b[\AA]$ & $12.003(9)$ & $12.041(4)$ \\
\hline$c[\AA]$ & $12.379(10)$ & $15.252(4)$ \\
\hline$\alpha\left[^{\circ}\right]$ & $97.378(8)$ & $66.845(14)$ \\
\hline$\left.\beta \Gamma^{\circ}\right]$ & $103.656(17)$ & $74.010(16)$ \\
\hline$\gamma\left[^{\circ}\right]$ & $94.000(11)$ & $70.156(13)$ \\
\hline$V /\left[\AA^{3}\right]$ & $969.7(13)$ & $1570.2(8)$ \\
\hline$Z$ & 2 & 1 \\
\hline$D_{\text {calc }}\left[\mathrm{Mg} / \mathrm{m}^{3}\right]$ & 1.492 & 1.498 \\
\hline Collected reflections & 6338 & 26983 \\
\hline Unique reflections & 3843 & 8470 \\
\hline Num. parapmeters & 263 & 395 \\
\hline$R$ & 0.0905 & 0.0412 \\
\hline$R_{w}{ }^{\mathrm{a}}$ & 0.2767 & 0.1050 \\
\hline Goodness-of-fit & 0.997 & 1.042 \\
\hline \multicolumn{3}{|c|}{${ }^{a} R_{W}=\left[\Sigma\left(\mathrm{w}\left(\mathrm{F}_{\mathrm{o}}{ }^{2}-\mathrm{F}_{\mathrm{c}}{ }^{2}\right)^{2}\right) / \Sigma \mathrm{w}\left(\mathrm{F}_{\mathrm{o}}^{2}\right)^{2}\right]^{1 / 2}$} \\
\hline
\end{tabular}

UV-visible spectroscopy. UV-visible spectra of the 30 complexes in DMSO solution were recorded using a Shimadzu MultiSpec-1500 spectrophotometer.

Luminescence spectroscopy. Emission and excitation spectra were recorded under various conditions using a Jasco FP-6600 spectrofluorometer. We dissolved each sample in DMSO and 35 then deaerated them via freeze-pump-thaw cycles before measurements. The sample concentrations were adjusted so that they had 0.1 absorbance at the excitation wavelengths. Luminescence quantum efficiency measurements. The luminescence quantum efficiency of each sample in a DMSO
40 solution was recorded using a HAMAMATSU C9920-02 absolute photoluminescence quantum yield measurement system equipped with integrating sphere apparatus and $150 \mathrm{~W}$ CW Xenon light source. We dissolved each sample in DMSO and then deaerated them via freeze-pump-thaw cycles before ${ }_{45}$ measurement. The sample concentrations were adjusted so that they had 0.1 absorbance at the excitation wavelengths. Owing to the low quantum yield of $\left[\mathrm{Pt}(\mathrm{Fl}-\mathrm{TSC})_{2}\right]$, the yield was measured by referring to the known luminescence quantum yield of riboflavin.

${ }_{50}$ Emission lifetimes. The emission lifetimes of each sample in DMSO solution were recorded using a HAMAMATSU C4780 Picosecond Fluorescence Lifetime Measurement System equipped with a nitrogen laser light source $(\lambda=337.1 \mathrm{~nm})$.

Theoretical calculations. Density functional theory (DFT) 55 calculations were performed on a 2CPU workstation UNIVD2G/Silent. Geometry optimization was achieved using the Becke3LYP functional and $6-31 \mathrm{G}^{*}$ basis set for riboflavin and the Fl-(H)TSC ligand, and the Becke3LYP functional and LANL2DZ basis set for the [Pt(FI-TSC) $)_{2}$ ] complex with a ${ }_{60}$ restricted Hartree-Fock formalism. We performed all DFT calculations using the Gaussian 03 program (Revision E.01SMP). ${ }^{21}$

\section{Acknowledgements}

This work was supported by a Grant-in-Aid for Scientific ${ }_{65}$ Research, Photochromism (No. 471), Young Scientists (B) (19750050) and the Global COE Program (Project No. B01: Catalysis as the Basis for Innovation in Materials Science) from MEXT, Japan.

\section{${ }_{70}$ Notes and References}

${ }^{a}$ Division of Chemistry, Faculty of Science, Hokkaido University, North10 West-8, Kita-ku, Sapporo 060-0810, Japan. Fax: 81-11-706-3447; Tel:81-11-706-3817; E-mail: akoba@sci.hokudai.ac.jp (A.K.), mkato@sci.hokudai.ac.jp (M. K.)

$75 \uparrow$ Electronic Supplementary Information (ESI) available: Emission lifetime decay profiles, cyclic voltamograms and the shapes of the HOMO-1 of Fl-(H)TSC and [Pt(Fl-TSC) 2 ]. See DOI: 10.1039/b000000x/

1 P. F. Heelis in Chemistry and Biochemistry of Flavoenzymes, Vol. 1 (Ed.: F. Muller), CRC Press, Boca Raton, Fl, 1991, pp. 171-193; J.

80 Cadet, P. Vigny in Bioorganic Photochemistry, Vol. 1 (Ed.: H. Morrison), Wiley, New York, 1990, pp. 1-272; S. Fukuzumi, T. Tanaka in Photoinduced Electron Transfer, Part C (Eds.: M. A. Fox, M. Chanon), Elsevier, Amsterdam, 1988, pp. 636-687.

2 Y. -M. Legrand, M. Gray, G. Cooke and V. M. Rotello, J. Am. Chem. Soc. 2003, 125, 15789-15795; A. Niemz and V. M. Rotello, Acc. Chem. Res. 1999, 32, 44-52; A. Niemz, J. Imbriglio and V. M. Rotello, J. Am. Chem. Soc. 1997, 119, 887-892; R. Miura, Vitamins, 1994, 68, 1-13.

3 C. Walsh, Acc. Chem. Res. 1980, 13, 148-155; T. C. Bruice, Isr. J. $90 \quad$ Chem. 1984, 24, 54-61; S. Ghisla and V. Massey, Eur. J. Biochem. 1989, 181, 1-17; F. Mueller in Topics in Current Chemistry Vol. 108 (Ed.: F. L. Boschke), Springer-Verlag, Berlin, 1983, pp. 71-108; H. Kasai and Z. Ymaizumi, J. Am. Chem. Soc. 1992, 114, 9692-9694; R. Epple, E. -U. Wallenborn and T. Carell, J. Am. Chem. Soc. 1997, 119, 7440-7451; P.F. Heelis, Chem. Soc. Rev. 1982, 11, 15-39.

4 E. C. Smith and D. E. Metzler, J. Am. Chem. Soc. 1963, 85, 32853288; P. -S. Song, E. C. Smith and D. E. Metzler, J. Am. Chem. Soc. 1965, 87, 4181-4184; K. Kino, H. Miyazawa and H. Sugiyama, Genes and Environment 2007, 29, 23-28; K. Kino, T. Kobayashi, E. 
Arima, R. Komori, T. Kobayashi and H. Miyazawa, Bioorg. Med. Chem. Lett. 2009, 19, 2070-2074.

5 M. Mansurova, M. S. Koay and W. Gartner, Eur. J. Org. Chem. 2008, 5401-5406; M. Murakami, K. Ohkubo and S. Fukuzumi, Chem. Eur. J. 2010, 16, 7820-7832.

6 S. Salzmann, V. Martinez-Junza, B. Zorn, S. E. Braslavsky, M. Mansurova, C. M. Marian and W. Gartner, J. Phys. Chem. A 2009, 113, 9365-9375; M. Insinska-Rak, E. Sikorska, J. L. Bourdelande, I. V. Khmelinskii, W. Prukala, K. Dobek, J. Karolczak, I. F. Machado,

10 L. F. V. Ferreira, A. Komasa, D. R. Worrall and M. Sikorski, J. Mol. Struct. 2006, 783, 184-190; S. Salzmann, J. Tatchen, C. M. Marian, J. Photochem. Photobiol. A 2008, 198, 221-231; A. Weigel, A. L. Dobryakov, M. Veiga and J. L. P. Lustres, J. Phys. Chem. A 2008, 112, 12054-12065.

157 I. Efimov and W. S. Mclntire, J. Am. Chem. Soc. 2005, 127, 732-741 A. O. Cuello, C. M. McIntosh and V. M. Rotello, J. Am. Chem. Soc. 2000, 122, 3517-3521; S. Miyazaki and T. Kojima. S. Fukuzumi, J. Am. Chem. Soc. 2008, 130, 1556-1557.

8 W. R. Frissell, C. W. Chung, C. G, Mackenzie, J. Biol. Chem. 1959, 234, 1297-1302; Y. Imada, H. Iida, S. Ono and S. Murahashi, J. Am. Chem. Soc. 2003, 125, 2868-2869; Y. Imada, H. Iida, S. Murahashi, T. Naota, Angew. Chem. Int. Ed. 2005, 44, 1704-1706; Y. Imada, H. Iida, T. Naota, J. Am. Chem. Soc. 2005, 127, 14544-14545; Y. Imada, T. Naota, The Chemical Record, 2007, 7, 354-361; J. Svoboda, H.

25 Schmaderer and B. Kcnig, Chem. Eur. J. 2008, 14, 1854-1865; H. Schmaderer, P. Hilgers, R. Lechner and B. Kenig, Adv. Synth. Catal. 2009, 351, 163-174

9 W. T. Garland Jr. and C. J. Fritchie, Jr., J. Biol. Chem. 1974, 249 2228-2234; N. K. Thallaj, D. Mandon and K. A. White, Eur. J. Inorg. Chem. 2007, 44-47.

10 D. X. West and A. E. Liberta, Coord. Chem. Rev. 1993, 123, 49-71; A. G. Quiroga and C. N. Ranninger, Coord. Chem. Rev. 2004, 248, 119-133; A. Castineiras, R. Pedrido, Inorg. Chem. 2008, 47, 55345536.

3511 A. G. Quiroga, J. M. Pérez, I. López-Solera, J. R. Masaguer, A. Luque, P. Román, A. Edwards, C. Alonso and C. Navarro-Ranninger, J. Med. Chem. 1998, 41, 1399-1408.

12 M. Wang. C. J. Fritchie Jr., Acta. Cryst. B 1973, 29, 2040-2045.

13 E. Bermejo, R. Carballo, A. Castineiras, R. Dominguez, A. E. Liberta,

C. Maichle-Mössmer, M. M. Salberg and D. X. West, Eur. J. Inorg. Chem. 1999, 965-973; D. X. West, G. A. Bain, R. J. Butcher, J. P. Jasinski, Y. Li, R. Y. Podniakiv, J. Valdes-Martinez, R. A. Toscano and S. Hernandez-Ortega, Polyhedron, 1996, 15, 665-674.

14 Platon; A. L. Spek, J. Appl. Cryst. 2003, 36, 7-13.

4515 P. Braunstein, R. Bender and J. Jud, Inorg. Synth. 1989, 26, 341-350.

16 H. H. Fall and H. G. Petering, J. Am. Chem. Soc. 1956, 78, 377-380

17 CrystalClear; Molecular Structure Corporation: Orem, UT, 2001.

18 SIR2004; M. C. Burla, R. Caliandro, M. Camalli, B. Carrozzini, G. L. Cascarano, L. De Caro, C. Giacovazzo, G. Polidori and R. Spagana, J. Appl. Cryst. 2005, 38, 381.

19 SHLEX-97; G. M. Sheldrick, Acta Crystallogr. Sect. A, 2008, 64, 112.

20 CrystalStructure 3.8; Crystal Structure Analysis Package, Rigaku and Rigaku/MSC (2000-2006). 9009 New Trails Dr. The Woodlands TX 77381 USA.

${ }_{55} 21$ Gaussian 03, Revision E.01, M. J. Frisch, G. W. Trucks, H. B. Schlegel, G. E. Scuseria, M. A. Robb, J. R. Cheeseman, J. A. Montgomery, Jr., J. T. Vreven, K. N. Kudin, J. C. Burant, J. M. Millam, S. S. Iyengar, J. Tomasi, V. Barone, B. Mennucci, M. Cossi, G. Scalmani, N. Rega, G. A. Petersson, H. Nakatsuji, M. Hada, M.

60 Ehara, K. Toyota, R. Fukuda, J. Hasegawa, M. Ishida, T. Nakajima, Y. Honda, O. Kitao, H. Nakai, M. Klene, X. Li, J. E. Knox, H. P. Hratchian, J. B. Cross, C. Adamo, J. Jaramillo, R. Gomperts, R. E. Stratmann, O. Yazyev, A. J. Austin, R. Cammi, C. Pomelli, J. W. Ochterski, P. Y. Ayala, K. Morokuma, G. A. Voth, P. Salvador, J. J. Dannenberg, V. G. Zakrzewski, S. Dapprich, A. D. Daniels, M. C. Strain, O. Farkas, D. K. Malick, A. D. Rabuck, K. Raghavachari, F. B. Foresman, J. V. Ortiz, Q. Cui, A. G. Baboul, S. Clifford, J. Cioslowski, B. B. Stefanov, G. Liu, A. Liashenko, P. Piskorz, I. Komaromi, R. L. Martin, D. J. Fox, T. Keith, M. A. Al-Laham, C. Y.
W. Chen, M. W. Wong, C. Gonzalez, J. A. Pople, Gaussian, Inc., Wallingford CT, 2004. 